\title{
Tissue-Specific Differential Expression of Two $\beta$-carbonic Anhydrases in Leucaena leucocephala Under Abiotic Stress Conditions
}

\author{
Archana Pal \\ Department of Molecular Biosciences and Bioengineering, University of Hawaii at Mānoa \\ Honolulu, HI 96822, USA \\ E-mail: apal@hawaii.edu
}

Dulal Borthakur (Corresponding author)

Department of Molecular Biosciences and Bioengineering, University of Hawaii at Mānoa Honolulu, HI 96822, USA

Tel: 1-808-956-6600, Fax: 1-808-956-3542. E-mail: dulal@hawaii.edu

Received: June 11, 2014 Accepted: July 12, 2014 Published: July 17, 2014

Doi: 10.5296/jab.v2i2.5797 URL: http://dx.doi.org/10.5296/jab.v2i2.5797

\begin{abstract}
Besides carbon fixation in plants, $\beta$-carbonic anhydrases ( $\beta$-CAs) have been shown to be involved in plant adaptation against some abiotic stress conditions. The objective of this research was to determine the expression levels of two isoforms of $\beta$-CAs under various stress conditions in different tissues of Leucaena leucocephala, a highly stress-tolerant tree-legume of tropics. The cDNAs for two $\beta$-CAs isoforms, one chloroplastic (cacp) and other cytoplasmic (cacyt) were isolated. These isoforms have $79 \%$ similarities at amino acid level, and their secondary structures, active site residues including zinc ligands, and the three-dimensional (3D) quaternary structures were found to be highly conserved and similar to those of the $\beta$-CA from Pisum sativum, which is structurally well-characterized. The $3 \mathrm{D}$-model of the two leucaena $\beta$-CAs predicted them as octameric proteins like the $\beta$-CA from $P$. sativum. The transcripts for cacp was found to be more abundant than the transcripts for cacyt in leaf and stem tissues, however the transcripts level of both $\beta$-CAs were similar in root tissues. The drought, salt, and light conditions caused up-regulation, and dark resulted down regulation of the cacp and cacyt transcripts. However, the changes in the expression
\end{abstract}




\section{Macrothink}

levels of cacp was more pronounced than those of cacyt, except in salt-stressed root tissues, which showed more pronounced up regulation of cacyt than that of cacp. This study suggests that abiotic stress conditions affecting the photosynthesis potential of plants also affect expression of different isoforms of $\beta$-CAs from $\mathrm{C}_{3}$ plants differentially, which may contribute to plants' survival under stress conditions.

Keywords: $\beta$-carbonic anhydrase, Leucaena leucocephala, Abiotic stress, Carbon fixation, $\mathrm{C}_{3}$ plants 


\section{Introduction}

Carbonic anhydrase (CA) is a ubiquitous enzyme that is known to exist in all living forms including, plants, algae, animals, prokaryotes and viruses. CAs have been classified in five different families; $\alpha, \beta, \gamma, \delta$, and $\zeta$ (Zimmerman \& Ferry, 2008; Moroney et al., 2011) and all these $\mathrm{CA}$ families catalyze the same biochemical reaction i.e. reversible hydration of carbon dioxide $\left(\mathrm{CO}_{2}\right)$ to form bicarbonate $\left(\mathrm{HCO}_{3}{ }^{-}\right)$and protons in a reaction represented as $\mathrm{CO}_{2}+$ $\mathrm{H}_{2} \mathrm{O} \leftrightarrow \mathrm{HCO}_{3}{ }^{-}+\mathrm{H}^{+}$. Among all CA families, only $\beta$-CA and $\zeta$-CA have small degree of sequence similarities at amino acid level; the sequences of other CA families do not exhibit any significant similarities with each other. First identified in spinach (Burnell et al., 1990; Fawcett et al., 1990), $\beta$-CAs have been reported to exist in eubacteria, algae, archaebacteria (Hewett-Emmett \& Tashian, 1996; Smith et al., 2002) and in all the species of fungi and plants (Hewett-Emmett, 2000; Götz et al., 1999). The $\beta$-CAs exist in different oligomeric states and previous crystallographic studies have identified dimeric, tetrameric and octameric $\beta$-CAs (Strop et al., 2001; Kimber \& Pai, 2000; Smith et al., 2000). CAs are metalloenzymes and most of the CAs require zinc ion as a prosthetic group. The zinc ion in the active site of CAs is coordinated by a zinc-binding hydrophobic pocket. The zinc-binding pocket of $\beta$-CAs is made of a histidine and two cysteine residues (Rowlett et al., 1994; Bracey et al., 1994). Additionally, a conserved aspartate residue in the active site of $\beta$-CAs has been suggested to be responsible for proton transport (Strop et al., 2001).

Based on different mechanisms for fixing inorganic carbon, plants can be categorized into Crassulacean acid metabolism (CAM), $\mathrm{C}_{4}$, and $\mathrm{C}_{3}$ plants and the role of $\beta$-CA differs in these plant groups (Burnell, 2000). In CAM and $\mathrm{C} 4$ plants, $\beta$-CAs act as the primary and first enzyme in $\mathrm{CO}_{2}$ fixation (Badger \& Price, 1994; Hatch \& Burnell, 1990). A $\beta$-CA from a $\mathrm{C}_{4}$ plant, Pennisetum glaucum, which is evolutionary very close to chloroplast $\beta$-CA isoform, has been shown to be differentially up-regulated under various abiotic stress conditions (Kaul et al., 2011), suggesting a possible new role of $\beta$-CAs in enhancing plants' capacity to withstand various abiotic stress conditions, in addition to the well-established role of carbon fixation. Such extensive study on $\beta$-CAs from $\mathrm{C}_{3}$ plants is lacking and hence the role of $\beta$-CAs in $\mathrm{C}_{3}$ plants is not well-defined.

$\beta$-CA is an abundant enzyme in the leaves of $\mathrm{C}_{3}$ plants and represents $\sim 2 \%$ of total protein (Okabeet al., 1984). In plants, the green tissues and roots both express $\beta$-CAs and they have been predicted to have diverse sub-cellular localization including chloroplasts, cytoplasm and mitochondria (Fabre et al., 2007; Tetu et al., 2007; Ludwig, 2012). However, only chloroplast-localized and cytoplasmic $\beta$-CAs have been suggested to have a role in carbon fixation (Syrjänen et al., 2010). Previously, two cDNAs, one each for chloroplastic and cytoplasmic $\beta$-CAs of Arabidopisis thaliana (Arabidopsis) were isolated and the transcript levels of these $\beta$-CAs were found to be regulated by light and dark conditions (Fett \& Coleman, 1994). This report also suggested that cytoplasmic $\beta$-CA from Arabidopsis may have non-photosynthetic roles. Considering (i) limited study on $\beta$-CAs from $\mathrm{C}_{3}$ plants, and (ii) possible role of $\beta$-CAs under abiotic stress conditions, it is important to study the role of chloroplastic and cytoplasmic $\beta$-CAs from a $\mathrm{C}_{3}$ plant that is highly tolerant to abiotic stress conditions. We chose to study $\beta$-CAs of a $\mathrm{C}_{3}$ plant Leucaena leucocephala (leucaena), which 
can withstand a variety of abiotic stress conditions including drought. In this study, we have isolated two leucaena cDNAs encoding chloroplastic and cytoplasmic $\beta$-CA isoforms and investigated their expression under various stress conditions.

\section{Materials and Methods}

\subsection{Plant Growth and Imitation of Stress Conditions}

Leucaena leucocephala cv. K-636 (leucaena) seeds were collected from University of Hawaii research station, Waimanalo, Honolulu. The mature seeds were scarified and surface sterilized as described previously (Pal et al., 2012). The surface sterilized seeds were germinated on half-strength Murashige and Skoog (MS) media for 2-3 days under sterile conditions at $28{ }^{\circ} \mathrm{C}$ in dark. Germinated seedlings were then grown in vermiculite for four weeks using Hoagland solution containing $5 \mathrm{mM} \mathrm{Ca}\left(\mathrm{NO}_{3}\right)_{2} \cdot \mathrm{H}_{2} \mathrm{O}, 2 \mathrm{mM} \mathrm{MgSO}_{4}, 5$ $\mathrm{mM} \mathrm{KNO} 3,1 \mathrm{mM} \mathrm{KH} \mathrm{PO}_{4}, 0.02 \mathrm{mM} \mathrm{FeSO}_{4} .7 \mathrm{H}_{2} \mathrm{O}, 0.02 \mathrm{mM}$ Na-EDTA, $0.045 \mathrm{mM}$ $\mathrm{H}_{2} \mathrm{BO}_{3}, 0.01 \mathrm{mM} \mathrm{MnCl}{ }_{2} \cdot \mathrm{H}_{2} \mathrm{O}, 0.8 \mu \mathrm{M} \mathrm{ZnSO}_{4}, 0.1 \mu \mathrm{M} \mathrm{NaMoO} \mathrm{Na}_{4} \cdot 2 \mathrm{H}_{2} \mathrm{O}$ and $0.3 \mu \mathrm{M}$ $\mathrm{CuSO}_{4} \cdot 5 \mathrm{H}_{2} \mathrm{O}$. The plants were maintained at $25 \pm 2{ }^{\circ} \mathrm{C}$ with $16 / 8 \mathrm{~h}$ dark photoperiod with an irradiance of $30 \mu \mathrm{mol} \mathrm{s} \mathrm{m}^{-1}$, unless otherwise stated. The plants were watered with Hoagland solution twice a week and water lost by evapotranspiration was compensated for by adding deionized water, daily. A few eight weeks old seedlings were used for RNA extraction, which later was used for isolating full-length cDNAs.

Eight weeks old leucaena plants were exposed to drought stress conditions by providing the plants with Hoagland solution supplemented with $15 \%$ polyethylene glycol (PEG 10000 ), the osmotic pressure of which is $\sim-3.02$ bars. The leaf, stem, and root samples were collected from the plants after 2, 6, 12, 24, 48, 72, and $96 \mathrm{~h}$ time points of treatment. For salt stress treatment, eight weeks old leucaena plants were watered with Hoagland solution containing $150 \mathrm{mM} \mathrm{NaCl}$ as used by (Kamal et al., 2012). The leaf, stem and root samples were collected after 1, 4, 6, 12, 24, and $48 \mathrm{~h}$ time points. Leaf, stem and root tissue samples isolated at same time points as those of treatments from leucaena plants that were watered only with Hoagland solution, without any addition of PEG or $\mathrm{NaCl}$, served as controls for drought and salt stress conditions. To study the effect of light and dark on the transcript level of cacp and cacyt, the eight weeks old plants were kept under light or dark conditions for 1, 3, 8, 16, 24, 36 and $48 \mathrm{~h}$. Plants grown under $16 \mathrm{~h}$ light and $8 \mathrm{~h}$ dark photoperiod served as control plants. The tissues collected from control plants just before the beginning of light photoperiod and dark photoperiod served as the controls for plants exposed to dark and light conditions, respectively. For bright light stress conditions eight weeks old plants were exposed to bright light $150 \mu \mathrm{mol} \mathrm{s}^{-1} \mathrm{~m}^{-2}$ for 1,3 and $8 \mathrm{~h}$. Controls were collected at the same time points as stress-treated plant from the plants grown under normal light condition. The collected samples from control and treatments were immediately frozen in liquid nitrogen and stored at $-80^{\circ} \mathrm{C}$ until used for RNA extraction.

\subsection{RNA Extraction and cDNA Synthesis}

Frozen samples of whole seedlings or their different tissues were finely grounded in liquid nitrogen and total RNA was extracted using Qiagen RNeasy plant mini kit (Qiagen, CA, 
USA) following the manufacturer's instruction. Total RNA was then treated with TURBO DNase (Ambion, TX, USA) for elimination of genomic DNA. The quality of RNA was verified by running $1 \mu \mathrm{g}$ of total RNA on $1 \%$ non-denaturing Agarose gel. First-strand cDNA was synthesized from $2 \mu \mathrm{g}$ of total RNA using MMLV reverse transcriptase (Promega, WI, USA).

\subsection{Isolation of Chloroplastic and Cytoplasmic $\beta$-Carbonic Anhydrase cDNA}

A $515 \mathrm{bp}$ partial cDNA fragment, homologous to $\beta$-CA, was obtained from interspecies suppression subtractive hybridization (iSSH) clones of leucaena (Negiet al., 2011). To extend the partial cDNA fragment at both 5'- and 3'-ends, RNA ligase-mediated rapid amplification of cDNA ends (RLM-RACE) was performed using First Choice ${ }^{\circledR}$ RLM-RACE Kit (Ambion) according to the manufacturer's instruction. For 5'-RACE of the cDNA fragment, 5'-ROP-cacp and 5'-RIP-cacp gene-specific primers (Table 1) were used with the 5'-RACE outer and 5'-RACE inner primers (Ambion) and for 3'-RACE of the cDNA fragment, 3'-ROP-cacp and 3'-RIP-cacp (Table 1) were used with 3-RACE outer and 3'RACE inner primer (Ambion). The 5'- and 3'-extended sequences were cloned in pGEMT-easy vector (Promega) and sequenced. The obtained sequences were then assembled to obtain the full-length cDNA for chloroplastic $\beta$-CA from leucaena.

Table 1. Primers used in this study and their description

\begin{tabular}{lll}
\hline Primer name & Sequence (5' to 3') & Description \\
\hline 5'-ROP-cacp & TGGGTGAAGATCGGTTTACCTGCA & These primers were used in the \\
5'-RIP-cacp & TGCTTGTGGTGGTATCAAGGGTCT & 5'-RLM-RACE of cacp \\
3'-ROP-cacp & ACTTGGTCCCACCATATTGCCAGA & These primers were used in the \\
3'-RIP-cacp & TCTCAAGGTGTCGGAAATCGTGGT & 3'-RLM-RACE of cacp \\
F-cacyt & ATCTTGAATTTCCAACCTGGTGAGGCTTT & These primers were used to \\
R-cacyt & CCTATCACCAAAATGTTCTCCACCTT & amplify 151bpcacyt \\
3'-RP-cacyt & TGAGGCTTTTGTGGTTCGCAACATCGC & These primers were used in the 5'- \\
5'-ROP-cacyt & CCACCTTTAAGTGCAACACTGC & and 3'-RLM-RACE of cacyt \\
\hline
\end{tabular}

To isolate leucaena cDNA for cytoplasmic carbonic anhydrase (cacyt), three nucleotide sequences for cacyt one each from Arabidopsis thaliana (gi|145362379), Ricinus communis (gi|255568811) and Populus trichocarpa (gi|224107828) were obtained from NCBI. Nucleotide sequences of these cacytwere compared using ClustalW and F-cacyt and R-cacytprimers were designed from the conserved regions (Table 1) and PCR was performed to amplify a partial cDNA fragment of cytoplasmic $\beta$-CA. The 5'- and 3'-ends of partial cDNA sequences for cacyt was extended by RLM-RACE using First Choice ${ }^{\circledR}$ RLM-RACE Kit (Ambion) according to the manufacturer's instruction. The gene-specific primers, 
5'-RP-cacyt was used in the 5'-RACE of the cacyt cDNA fragment whereas, 3'-RP-cacyt was used in the 3'-RACE (Table 1). The PCR products obtained as a result of 5'- and 3'-RACE were cloned in pGEMT-easy vector (Promega) and sequenced. The resultant sequences were then assembled to obtain the full-length cDNA for cytoplasmic $\beta$-CA from leucaena.

\subsection{Sequence Analyses and Prediction of Sub-Cellular Localization}

The homology searches of the partial and full-length cDNA sequences for the leucaena $\beta$-CAs were carried out using BLASTx program of NCBI against its reference protein database. The homology searches for the deduced amino acid sequences were performed using BLASTp program of NCBI against its reference protein database. The open reading frame (ORF) for each of the full-length cacp and cacyt were identified using 'ORF finder' tool of sequence manipulation suite. The deduced amino acid sequence for cacp and cacyt were then studied using TargetP 1.1 server (Emanuelsson et al., 2000) to predict their sub-cellular location. The TargetP 1.1 server predicts the sub-cellular location of eukaryotic proteins based on the presence of $\mathrm{N}$-terminal pre-sequences such as chloroplast transit peptide, mitochondrial signal peptide and secretory pathway signal peptide. In this analysis 'Plant' was selected as the 'organism group' considering that the cacp and cacyt are of plant origin. The cleavage site prediction was also performed in this analysis.

\subsection{In Silico Structural Analysis of Leucaena $\beta$-CAs}

In order to study the secondary structure and active site architecture of leucaena $\beta$-CAs, the $\beta$-CA from the $\mathrm{C}_{3}$ plant Pisum sativum (gi|8569250) was used as a reference sequence as its X-Ray crystallographic structure has already been resolved (Kimber \& Pai, 2000). The $\beta$-CA amino acid sequences of leucaena and Pisum sativum were studied for their secondary structure using the PSIPRED server (McGuffinet al., 2000). The prediction method selected for analysis was PSIPRED v3.0. The signal peptide region of the chloroplastic $\beta$-CA was eliminated for analysis. The conserved regions in the chloroplastic $\beta$-CA of leucaena was determined by comparing its sequence with other chloroplastic $\beta$-CAs from $\mathrm{C}_{3}$ plants including Glycine max (gi|356511666), Medicago truncatula(gi|357495985), Populus trichocarpa (gi|224055529), Vitis vinifera (gi|225452452, Ricinus communis (gi|255567325) and Arabidopsis thaliana (gi|30678353), whereas the conserved region of cytoplasmic $\beta$-CA of leucaena was identified by its comparison with cytoplasmic $\beta$-CAs of A. thaliana (accession NM_202390.2), $R$. communis (accession XM_002525331.1), and $P$. trichocarpa (accession XM_002314581.1). The homology-based modeling of three-dimensional (3D) structures of CAcp and CAcyt proteins were performed using SWISS-MODEL server (Arnold et al., 2006; Schwede et al., 2003; Guex \& Peitsch, 1997).

\subsection{Expression Analyses of cacp and cacyt}

The designing of specific primers for cacp and cacyt and optimization of RT-PCR condition are described in Supplementary material (SM1, Table S1, and Figure S1). The semi-quantitative tissue specific expression of cacp and cacyt is described in Supplementary materials (SM2, and Figure S2). The suitable internal reference genes were 
identified using the method as described previously by Negiet al., 2011. The results for identification of suitable internal reference gene are shown in Supplementary material (SM3, and Figure S8). For expression analysis of cacp and cacyt, the quantitative real-time PCR (qPCR) was performed using the $1 \mu 1$ of 10 -fold diluted cDNA from control and treatments in a $15 \mu \mathrm{l}$ of reaction consisting of $0.3 \mu \mathrm{l}$ each of $10 \mu \mathrm{M}$ forward and $10 \mu \mathrm{M}$ reverse primer, and $1 \mathrm{X}$ iQ SYBR Green Supermix (Bio-Rad, Hercules, CA, USA). The reactions were carried out in Mini Opticon system (BioRad) and the qPCR parameter consisted of initial denaturation of $95{ }^{\circ} \mathrm{C}$ for $5 \mathrm{~min}$ and then 32 cycles of $95{ }^{\circ} \mathrm{C}$ for $15 \mathrm{~s}$, $52{ }^{\circ} \mathrm{C}$ (for cacp) and $62{ }^{\circ} \mathrm{C}$ (for cacyt) for $20 \mathrm{~s}$, and $72{ }^{\circ} \mathrm{C}$ for $25 \mathrm{~s}$, followed by a final annealing for $5 \mathrm{~min}$ at $72^{\circ} \mathrm{C}$. In each $\mathrm{qPCR}$ reaction the specificity of primers were confirmed by performing melting curve analysis of the amplified products. The $\mathrm{Ct}$ values of control and treatments were recorded and were used for calculating the transcript expression levels under each condition. For each qPCR assay two biological and three PCR replicates were used. The Livak method (Livak \& Schmittgen, 2001) was used to quantify the relative expression of the target gene normalized to that of the selected internal reference gene.

\section{Results}

\subsection{Isolation of Chloroplastic and Cytoplasmic $\beta$-CA From Leucaena}

The 515 bp partial sequence that was obtained from the iSSH clones of leucaena showed high homology with the carbonic anhydrase of M. truncatula in BLASTx analysis against reference protein database. The homology between the two sequences exhibited $82 \%$ identical and 90\% positive amino acid residues (Supplementary materials, Figure S3). The sub-cellular localization of this partial sequence was uncertain at this point, therefore, we used the term ' $\beta$-CA1' for this leucaena $\beta$-CA cDNA fragment until its localization was predicted. The 5'- and 3'-RACE of $\beta$-CA1 resulted in the addition of $569 \mathrm{bp}$ at the 5 '-end and $65 \mathrm{bp}$ at the 3 '-end, respectively. This resulted in a total of $1149 \mathrm{bp}$ long $\beta$-CA1 sequence with $34 \mathrm{bp} 5$ '-UTR and $134 \mathrm{bp} 3$ '-UTR. The ORF of the $\beta$-CA1 was found to be $981 \mathrm{bp}$ with the deduced amino acid sequence of 326 residues. The BLASTp analysis of the deduced amino acid sequence of $\beta$-CA1 exhibited strong homology with the chloroplastic $\beta$-CA from Glycine max. Both the sequences share $76 \%$ identical and $85 \%$ positive amino acid residues (Supplementary materials, Figure S4). The high homology of $\beta$-CA1 with the chloroplastic carbonic anhydrase of $G$. max indicates that the $\beta$-CA1 may be a chloroplastlocalized enzyme. However, to further verify its location, the amino acid sequence of $\beta$-CA1 was subjected to the TargetP1.1 server using the plant networks. The $\beta$-CA1 was predicted to have an $\mathrm{N}$-terminal chloroplast signal peptide with the reliability class value of 1 , which is the strongest confidence value of prediction (Table 2). The identified chloroplast transit peptide consists of 36 amino acids with the sequence 'MSTASINGCCLSSFSSSKTSLPSKFSVSARLATPPP'. This suggests that the $\beta$-CA1 encodes a chloroplast-localized protein and hence we termed the cDNA as 'chloroplastic $\beta-\mathrm{CA}^{\prime}($ cacp $)$. 
After identifying and isolating the leucaena cDNA for chloroplastic $\beta$-CA, the next goal was to isolate the leucaena cDNA for cytoplasmic $\beta$-CA (cacyt). The PCR using leucaena cDNA as the template and F-cacyt and R-cacyt as the primers resulted in the amplification of a $151 \mathrm{bp}$ sequence. Despite the small sequence coverage (50 amino acid), the BLASTx analysis of the resulted sequence showed high homology with the $\beta$-CA of $A$. thaliana with $86 \%$ identities and $94 \%$ positives residues (Supplementary materials, Figure S5). The 5'- and 3'-RACE resulted in the addition of $416 \mathrm{bp}$ at the 5'-end and 443 bp additions at the 3 '-end of the $151 \mathrm{bp}$ partial sequence of leucaena $\beta$-CA. The final sequence assembled after 5'- and 3'-RACE consists of 1010 bp with 129 bp long 5'-UTR and $119 \mathrm{bp}$ long 3'-UTR. The 1010-bp long cDNA has a 762-bp long ORF, which encodes for a $\beta$-CA with 253 amino acid residues. The BLASTp analysis of the full-length deduced amino acid sequence of leucaena $\beta$-CA exhibited strong homology with the carbonic anhydrase from M. truncatula with $79 \%$ identities and $90 \%$ positives (Supplementary materials, Figure S6). The sub-cellular localization of this sequence was predicted using TargetP1.1 server. The sequence was predicted to have no signal peptide with high reliability class value of 2 (Table 2 ), suggesting it to be a cytoplasmic $\beta$-CA. The GenBank accession numbers for chloroplastic and cytoplasmic $\beta$-CA from L. leucocephala are KC924756 and KC924757, respectively.

Table 2. Prediction of sub-cellular localization of the CAcp and CAcyt protein of leucaena using TargetP 1.1 server

\begin{tabular}{|c|c|c|c|c|c|c|c|}
\hline \multirow{2}{*}{$\begin{array}{l}\text { Protein } \\
\text { (amino acid } \\
\text { residues) }\end{array}$} & \multicolumn{3}{|c|}{$\begin{array}{l}\text { Signal peptide neural network score } \\
\text { on which final prediction is based }\end{array}$} & \multirow[b]{2}{*}{ Other } & \multirow[b]{2}{*}{ Location } & \multirow{2}{*}{$\begin{array}{l}\text { Reliability } \\
\text { Class* }\end{array}$} & \multirow{2}{*}{$\begin{array}{l}\text { Signal } \\
\text { peptide } \\
\text { length }\end{array}$} \\
\hline & $\begin{array}{l}\text { Chloroplast } \\
\text { transit } \\
\text { peptide }\end{array}$ & $\begin{array}{l}\text { Mitochondri } \\
\text { al transit } \\
\text { peptide }\end{array}$ & $\begin{array}{l}\text { Secretory } \\
\text { protein }\end{array}$ & & & & \\
\hline CAcp (323) & 0.974 & 0.38 & 0.012 & 0.023 & Chloroplast & 1 & 36 \\
\hline CAcyt (253) & 0.041 & 0.162 & 0.143 & 0.876 & - & 2 & - \\
\hline
\end{tabular}

* Reliability class (RC), from 1 to 5 , where 1 indicates the strongest prediction.

\subsection{In Silico Structural Analysis of Leucaena CAcp and CAcyt}

$\beta$-CAs in general has high homology and conserved secondary structure irrespective of their different sub-cellular localization. Therefore, to compare the sequence similarity between cacp and cacyt encoded proteins (CAcp and CAcyt), the deduced amino acid sequences of the two $\beta$-CAs from leucaena were aligned using ClustalW. The signal peptide region of the CAcp was eliminated from the alignment.

The two sequences showed high homology with $64 \%$ identical and $79 \%$ similar amino acid residues (Supplementary materials, Figure S7). For secondary structure analysis, the well 


\section{Macrothink Institute ${ }^{\mathrm{TM}}$}

resolved and studied $\beta$-CA from the $\mathrm{C}_{3}$ plant $P$. sativum (gi|8569250) was used as the reference. The secondary structure of $\beta$-CA from $P$. sativum follows a pattern of $\alpha$-helix and $\beta$-strand in a sequence of $(\alpha 1, \alpha 2, \beta 1, \beta 2, \alpha 3, \beta 3, \alpha 4, \alpha 5, \alpha 6, \alpha 7, \beta 4, \beta 5)$. We identified the same sequential pattern of $\alpha$-helix and $\beta$-strand in the predicted secondary structure of CAcp and CAcyt (Figure 1).

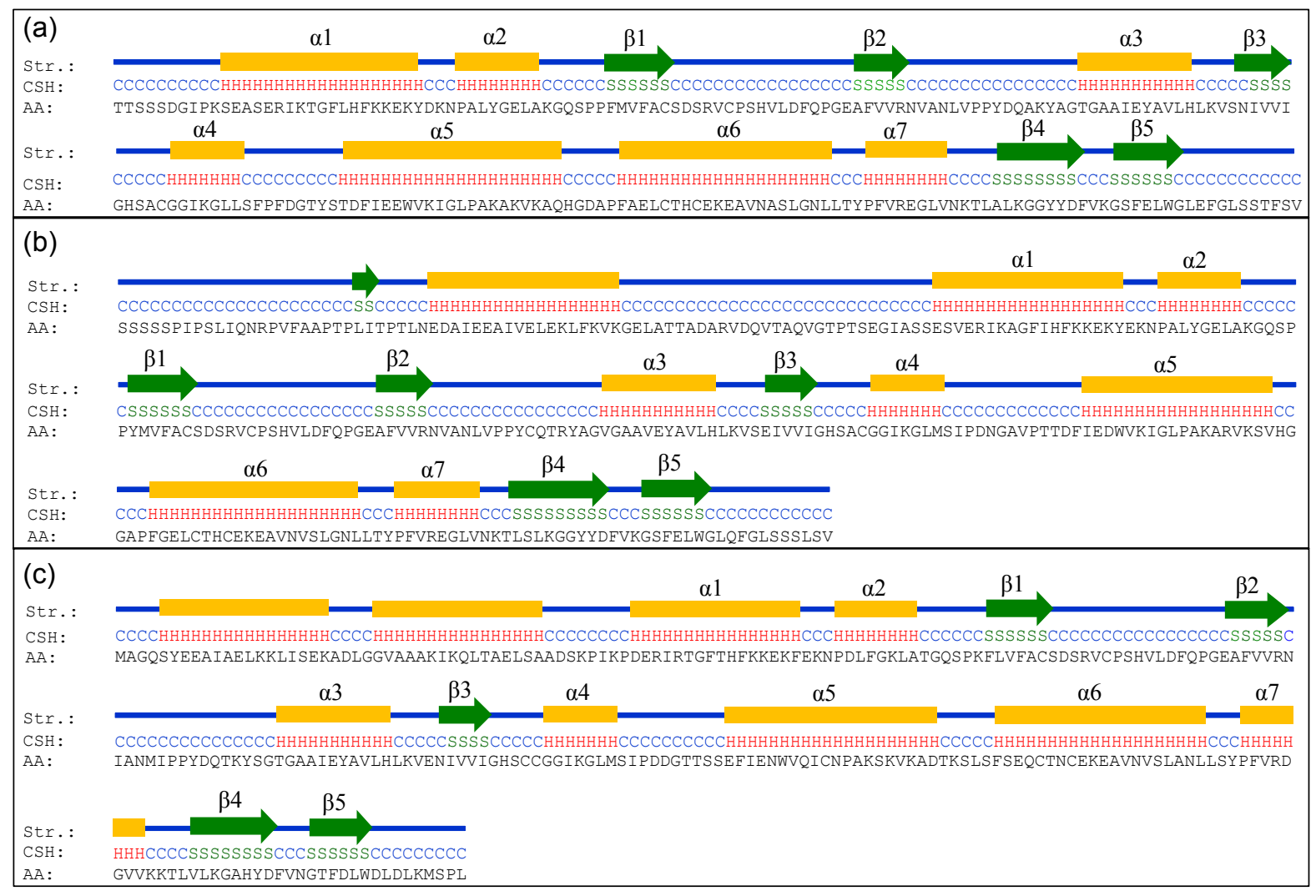

Figure 1. Prediction of secondary structure of chloroplastic $\beta$-CA (b) and cytoplasmic $\beta$-CA (c) from L. leucocephala. The $\beta$-CA from P. sativum (a) was used as a reference

There are some carbonic anhydrase-related proteins such as CARP VIII, CARP X and CARP XI, which, despite high homology with carbonic anhydrases, lack the functional activity because of substitution in one or more zinc-binding ligands (Sly \& $\mathrm{Hu}, 1995$ ). Therefore, it was important to identify the presence of zinc ligands in leucaena carbonic anhydrase. To study the active site architecture of leucaena $\beta$-CAs, the amino acid sequence of CAcp and CAcyt were compared with other chloroplastic and cytoplasmic $\beta$-CAs, respectively. Since the zinc ligands in functional $\beta$-CAs consist of one histidine and two cysteine residues, the sequences were first screened for the conserved histidine and cysteine residues. Leucaena CAcp, when compared with chloroplastic $\beta$-CAs of $G$. max, M. truncatula, $P$. trichocarpa, $V$. vinifera, $R$. communis and $A$. thaliana, showed three conserved histidine (His-162, His-202, and His-213) and three conserved cysteine residues (Cys-153, Cys-159, and Cys-216), whereas leucaena CAcyt, which was compared with the 
cytoplasmic $\beta$-CAs of $A$. thaliana, $R$. communis and $P$. trichocarpa exhibited 4 conserved histidine (His-96, His-136, His-147 and His-233) and 6 conserved cysteine (Cys-87, Cys-93, Cys-149, Cys-150, Cys-197 and Cys-200) residues. To identify the zinc ligands among these conserved histidine and cysteine residues, the CAcp and CAcyt of leucaena were compared with the well-studied structure of $C_{3} \beta$-CAs. It appears that the Cys- 153 at the end of $\beta-1$ strand, Cys-216 before the beginning of $\alpha-4$ helix and His-213 after $\beta-3$ strand are the zinc ligands in leucaena CAcp and Asp-155 is the conserved residue for the proton transport required in the $\beta$-CA-catalyzed reactions (Figure 2).

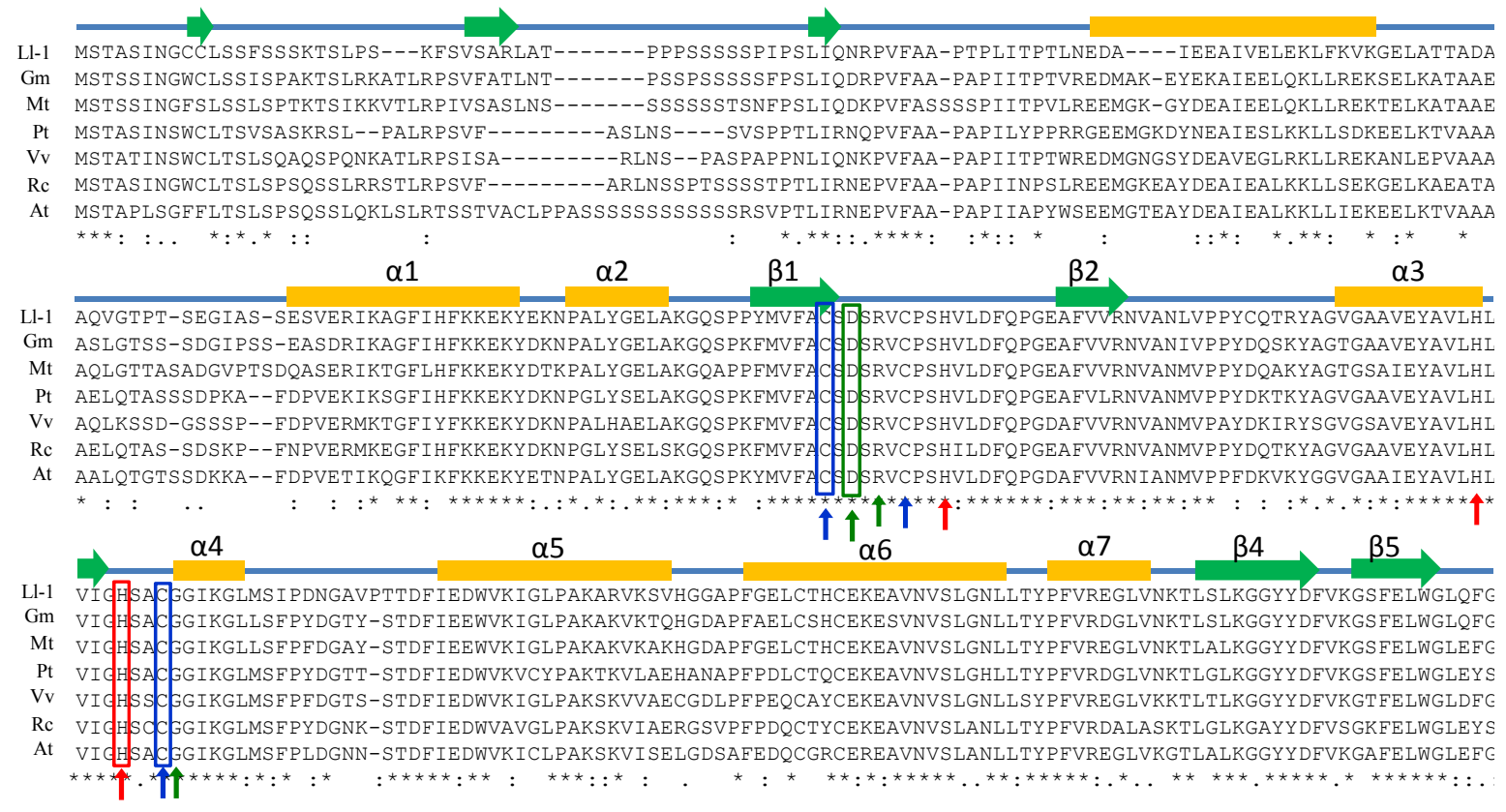

Figure 2. Chloroplastic $\beta$-CA of leucaena (Ll-1) was compared with the chloroplastic $\beta$-CAs of G. $\max (\mathrm{Gm})$, M. truncatula $(\mathrm{Mt})$, P. trichocarpa $(\mathrm{Pt}), V$. vinifera $(\mathrm{Vv}), R$. communis (Rc) and A. thaliana (At). The conserved histidine and cysteine residues are represented by red and blue arrows, respectively. The green arrows represent some other conserved residues important in the active site of $\beta$-CAs. The cysteine and histidine residues in the blue and red rectangular boxes represent the zinc ligand and the aspartate shown in the green rectangular box is the residue involved in the proton transport step in $\beta$-CA catalyzed reactions

In CAcyt, it is likely that the Cys-87, Cys-139 and His-147 are the zinc ligand in CAcyt of leucaena and the Asp-89 is the residue involved in the proton transport (Figure 3). 


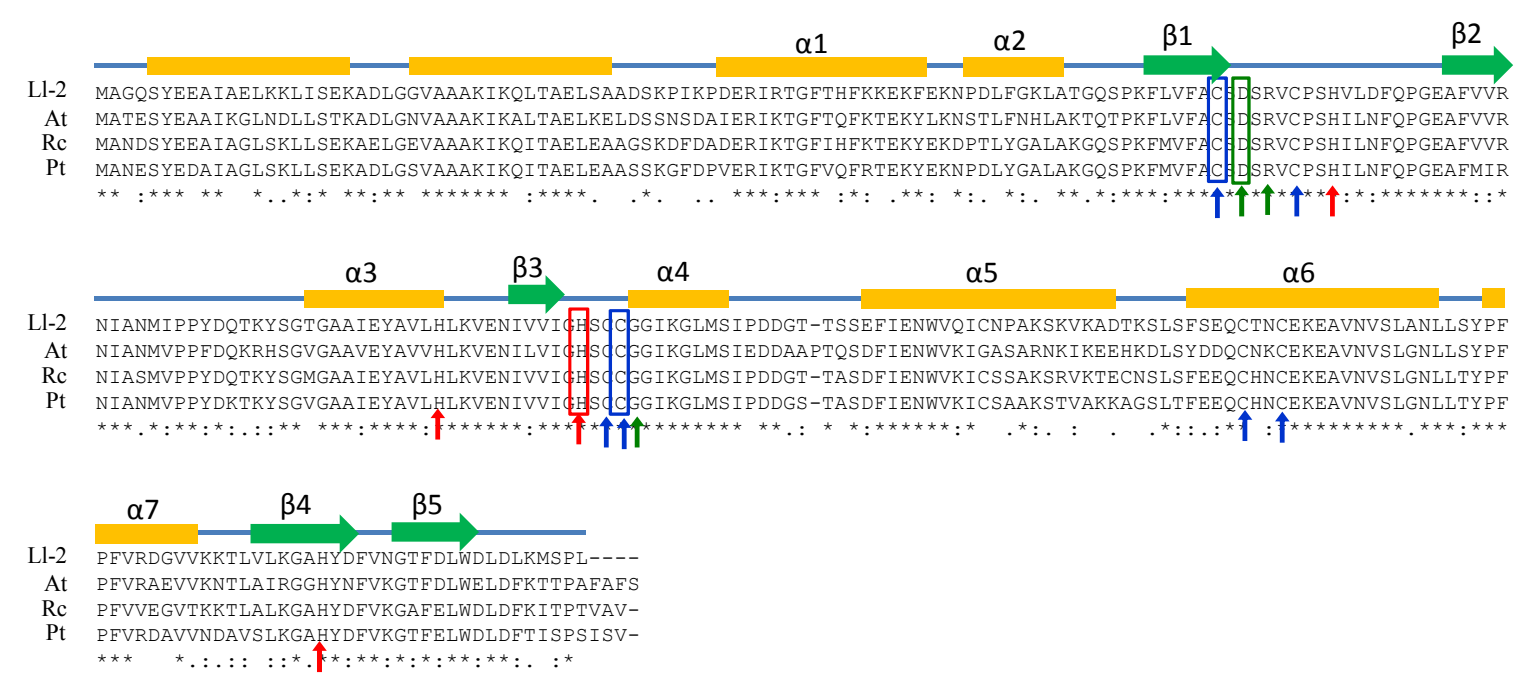

Figure 3. Cytoplasmic $\beta$-CA of leucaena (L1-2) was compared with the cytoplasmic $\beta$-CAs of A. thaliana (At), R. communis (Rc) and P. trichocarpa $(\mathrm{Pt})$. The conserved histidine and cysteine residues are represented by red and blue arrows, respectively. The green arrows represent some other conserved residues important in the active site of $\beta$-CAs. The cysteine and histidine residues in the blue and red rectangular boxes represent the zinc ligand and the aspartate shown in the green rectangular box is the residue involved in the proton transport step in $\beta$-CA catalyzed reactions

Although the $\beta$-CAs can be found in various oligomeric states, the fundamental structural unit of $\beta$-CA is a dimer (Rowlett, 2010). Therefore, to predict the oligomeric state of the two $\beta$-CA isoforms we performed the three-dimensional (3D) quaternary structure prediction of CAcp and CAcyt using the protein structure homology-modeling server; SWISS-MODEL (Arnold et al., 2006; Schwede et al., 2003). Based on the highest homology the SWISS-MODEL server selected the X-ray crystallographic structure of $\beta$-CA from the $\mathrm{C}_{3}$ dicot $P$. sativumas the template structure and build the quaternary structure of both CAcp and CAcyt as octameric proteins (Figure 4). All the amino acid residues that interact with $\mathrm{Zn}$ ligand were found to be completely conserved between models and template. The predicted secondary structure, conserved active site residues, and 3D-model structure of CAcp and CAcyt suggest that these two leucaena $\beta$-CAs are octameric proteins and have all the essential elements that are required for the activity of functional $\beta$-CAs. 

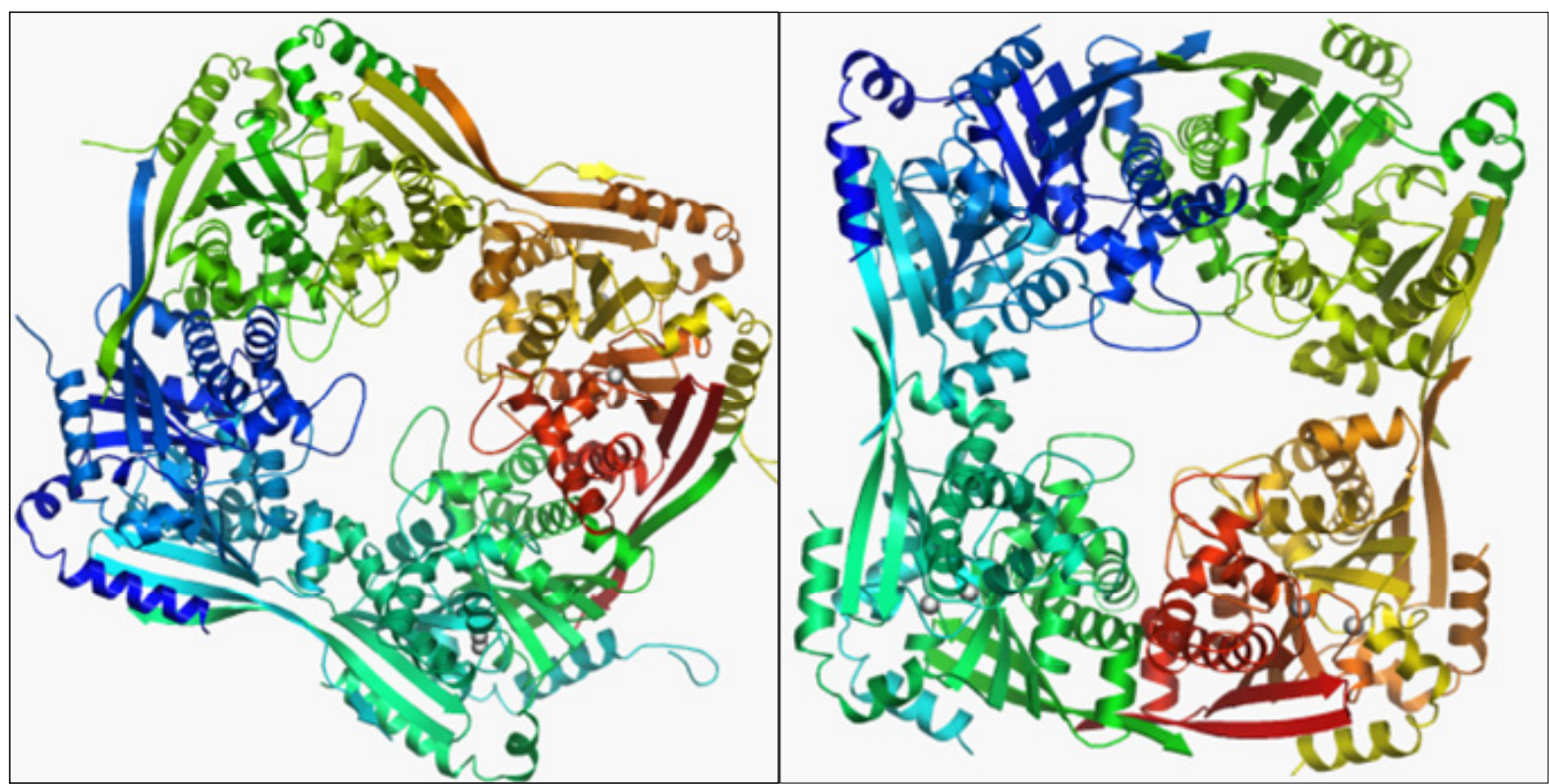

Figure 4. The 3D model of CAcp (a) and CAcyt (b) were build using SWISS-MODEL server. Both the models were predicted to be octameric proteins and each monomeric unit (polypeptide chain) of the proteins is represented in different color

\subsection{Effects of Drought and Salt Stress Conditions on the Expression of cacp and cacyt}

To determine the effects of drought and salt stress conditions on the expression of two $\beta$-CAs, the leucaena samples from different tissues exposed to drought stress conditions were collected at 2, 6, 12, 24, 48, 72, and $96 \mathrm{~h}$ of treatment. In the drought-exposed leaf tissues, the transcript of cacp increased up to $\sim 6$-fold in first $24 \mathrm{~h}$; however, its expression sharply increased to $\sim 17$-fold in $48 \mathrm{~h}$, which then remained unchanged at further time points. The stem tissues exhibited $\sim 3$-fold increase in the cacp transcript level in $24 \mathrm{~h}$, which then increased to $\sim 8$-fold in $48 \mathrm{~h}$ and remained unchanged thereafter. The expression of cacyt in drought-stressed leaf and stem samples did not show much increase in the expression. In leaf tissues, the expression of cacyt increased to $\sim 2$-fold in $24 \mathrm{~h}$, which further increased to $\sim 4$-fold in $48 \mathrm{~h}$, and remained unchanged in further time points. The stem tissues showed maximum increase of $\sim 2$-fold in the cacyt expression in $24 \mathrm{~h}$ and got stabilized at this level in subsequent time points. No significant change in the transcript level of cacp and cacyt was observed in the root tissues from the drought-exposed plants (Figure 5a-b).

Different tissue samples of leucaena from salt stress-treated plants were collected at 1, 4, 6, 12,24 , and $48 \mathrm{~h}$ time points. The leaf tissues showed increase in the transcript levels of both cacp and cacyt. As compared with the transcript levels of cacyt, the overall increases in cacp expression level were more pronounced in leaf and stem tissues, however, the root tissues showed more up regulation of cacyt, than that of cacp. The cacp transcript level in leaf tissues first increased to $\sim 6$-fold in $1 \mathrm{~h}$ followed by nearly 15 -fold increases in 4 and 6 $\mathrm{h}$ of treatment. In further time points of salt treatment, including 12,24 , and $48 \mathrm{~h}$, the 
increases in cacp transcript level compared to the expression level of control tissues were only $\sim 10$-, 3- and 2-fold, respectively. The stem tissues exhibited $\sim 2$ - to 7-fold increases in the levels of cacp transcripts in first $12 \mathrm{~h}$ of treatment. The cacp transcript level in the subsequent time points was almost similar to those of controls. The cacp transcript levels in salt-stressed root tissues were found to be $\sim 2$ to 3 -fold higher in 1 to $24 \mathrm{~h}$ time points, and at $48 \mathrm{~h}$ there was no significant change observed. The cacyt transcript level in salt-stressed leaf tissues increased to $\sim 5$ - to 6 -fold in 1 to $24 \mathrm{~h}$ time points and it decreased to 2 -fold in $48 \mathrm{~h}$. In stem tissues, the cacyt transcript level increased to $\sim 2$ - to 6 -fold in 1 to $6 \mathrm{~h}$ time points. At $12 \mathrm{~h}$ of treatment, there was only a 3 -fold increase in the transcript level of cacyt, which then became similar to the control in $24 \mathrm{~h}$ and remained unchanged until 48 $\mathrm{h}$. The transcript level of cacyt in root tissues first increased to $\sim 5$ - to 10 -fold in 1 to $6 \mathrm{~h}$ and then became stabilized at $\sim 4$ - to 5-fold in $12 \mathrm{~h}$ (Figure $5 \mathrm{c}-\mathrm{d}$ ).

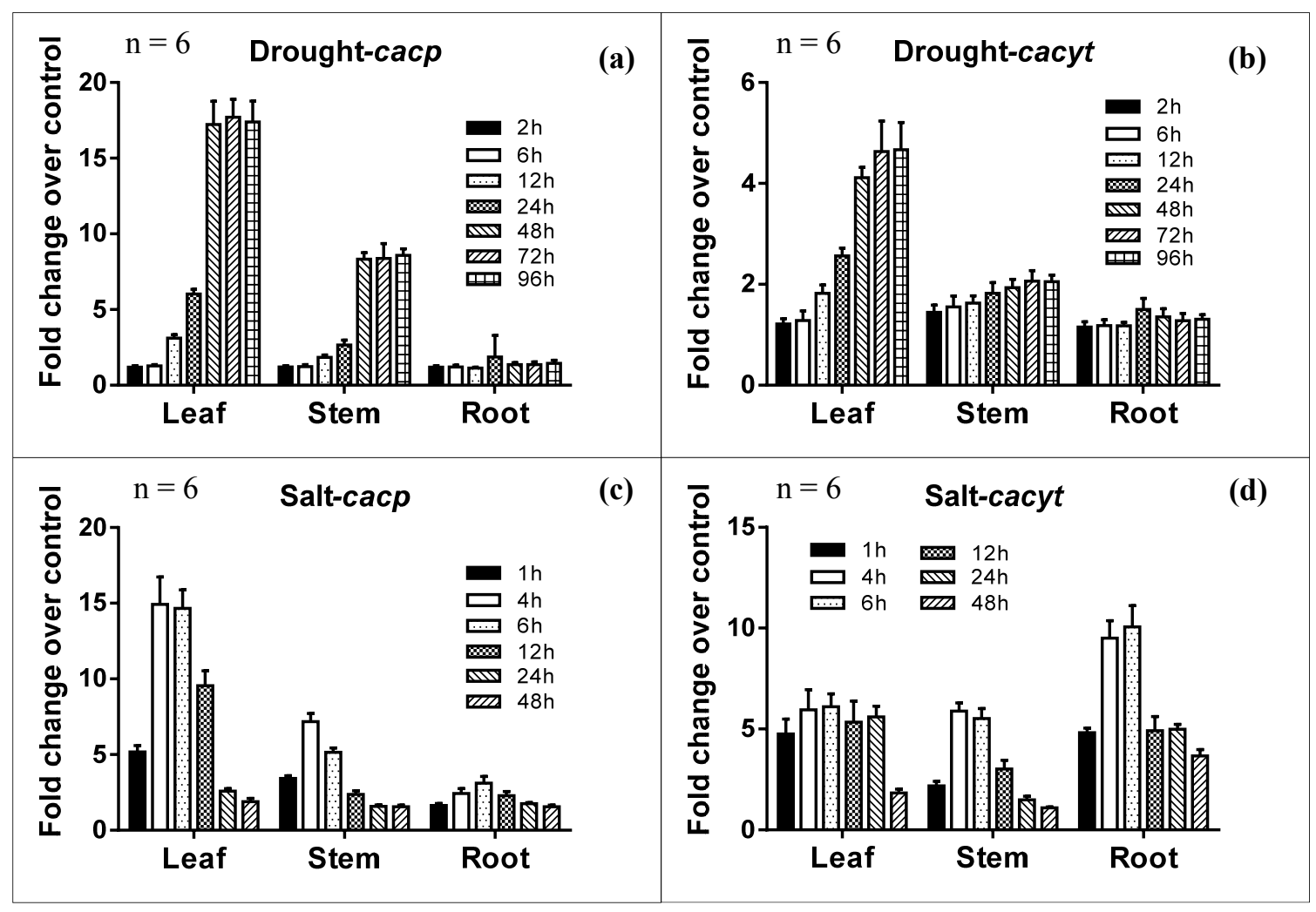

Figure 5. Tissue-specific differential expression of cacp and cacyt from L. leucocephala exposed to drought (a-b) and salt stress (c-d) conditions. The bars represent mean fold change in expression of gene compared to that of control, whereas the error bar represents the standard deviation. The statistical significance was calculated using a two-way ANOVA 
3.4 Effects of Light, Bright Light, and Dark on the cacp and cacyt Transcripts

Under light conditions the cacp and cacyt transcripts showed increased expressions in leaf and stem tissues. The root tissues did not show any significant changes in the levels of cacp and cacyt transcripts. The cacp and cacyt transcript levels in leaf and stem tissues first exhibited a gradual increase until $16 \mathrm{~h}$ of treatment and then became stabilized in further time points. The cacp transcript levels in leaf tissues first increased from $~ 9$ - to 34-fold in 1 to $16 \mathrm{~h}$ time and remained at the same level in further time points. The effect of light on the cacp transcript levels in leaf tissues was less pronounced than that of cacp. The cacp transcript levels first increased from $\sim 3$ - to 11-fold and then remained at the same level in further time points. In stems, the cacp transcript levels increased to $\sim 6$ - to 24 -fold in 1 to $24 \mathrm{~h}$ of treatments after which no further increase in cacyt transcript levels was observed. The cacyt transcript levels, on the other hand, increased only from $\sim 6$ - to 10-fold in 1 to 48 h time points (Figure 6a-b).

Bright light conditions, as compared with moderate light that served as the control, induced only small changes in the level of cacp and cacyt transcripts and we did not observe fluctuation in changes in different time points. The level of cacp transcripts exhibited small increases in the leaf and stem tissues. The increase in the cacp transcripts was found to be $\sim 2$ - to 4 -fold in leaf tissues and $\sim 2$-fold in stem tissues. The cacyt transcript level showed 2-fold increase in leaf tissues. The transcript levels of cacp in root tissues and the transcript levels of cacyt in stem and root tissues did not show any change compared to those of controls.

Other than root tissues, the leaf and stem exhibited significant decrease in the transcript levels of both cacp and cacyt under dark conditions. In leaf tissues, the decrease in cacp level was found to be $\sim 4$ - to 22 -fold in 3 to $24 \mathrm{~h}$ of treatment and no further decrease was observed in the subsequent time points. The cacyt transcript level showed decrease of $\sim 9$-fold in $8 \mathrm{~h}$ and then remained at the same level in further time points. In stems, the decreases in the cacp and cacyt transcript levels were found to be $\sim 3$ - to 10 -fold and $\sim 2$ - to 5 -fold, respectively. The root tissues, however, did not exhibit any significant decrease in the transcript levels of cacp and cacyt. 


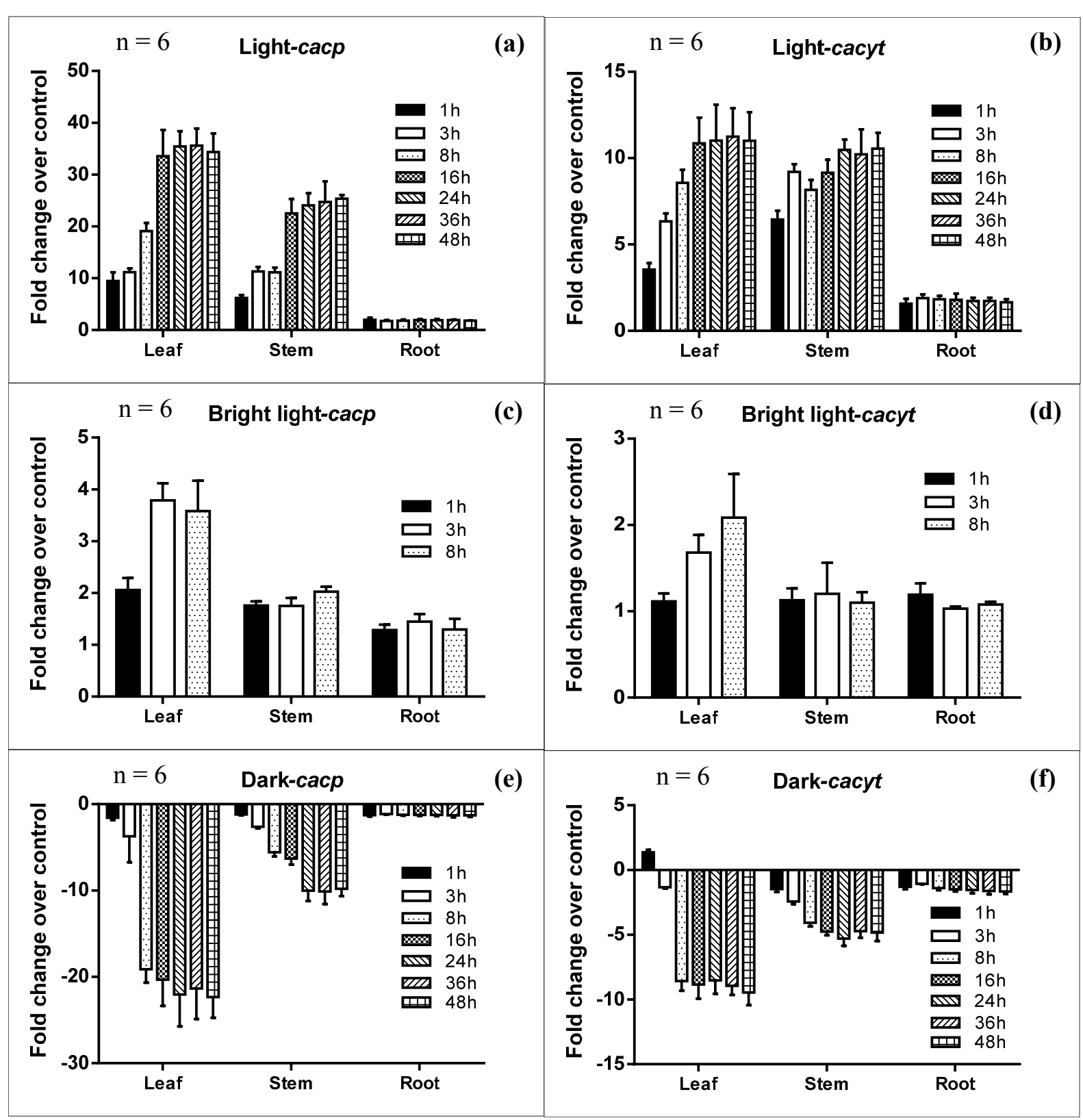

Figure 6. Effect of light (a-b), bright light (c-d), and dark (e-f) conditions on the tissue-specific expressions of cacp and cacyt from L. leucocephala. The bars represent mean fold change in expression of cacp or cacyt compared to that of control, whereas the error bar represents the standard deviation. The statistical significance was calculated using a two-way ANOVA.

\section{Discussion and Conclusion}

$\beta$-CAs have been well-studied in CAM and $\mathrm{C}_{4}$ plants in which most of the $\mathrm{CO}_{2}$ that is fixed comes through $\beta$-CAs (Badger \& Price, 1994). In these plants, $\beta$-CAs act as a primary enzyme in the $\mathrm{CO}_{2}$ fixation. However, the role of $\beta$-CAs in $\mathrm{C}_{3}$ plants is inexplicit because of limited study. Therefore, the goal of this research was to isolate cDNA sequence for 
chloroplastic and cytoplasmic $\beta$-CAs fromleucaena, a $\mathrm{C}_{3}$ plant and to study the effects of various stress conditions on the expression of leucaena $\beta$-CAs. In this report, we isolated two full-length cDNAs for $\beta$-CAs from leucaena and studied their expression in various stress conditions. Although the sub-cellular localization of one of these $\beta$-CAs was predicted to be chloroplastic (cacp) and the other as cytoplasmic (cacyt), their amino acid sequences were $79 \%$ similar and both have similar secondary structures.

Carbonic anhydrase-related proteins (CARPs) such as CARP VIII, CARP X and CARP XI, are homologous to carbonic anhydrases but lack the functional activity because of substitution in one or more amino acid residues involved in zinc binding. Therefore, for a functionally active CA it is important to have all the zinc-binding residues at the active site of the enzyme. Moreover, the enzyme should have all the conserved folds as found in functionally active forms of CAs. Therefore, for analyzing structural folds and active site residues, we used structurally resolved $\beta$-CA from P. sativum (Kimber \& Pai, 2000) as the reference. The secondary structure of both the $\beta$-CAs from leucaena was found conserved and followed the same sequential pattern of $\alpha$-helixes and $\beta$-strands as found in the $\beta$-CA from $P$. sativum. A previous study on spinach $\beta$-CA identified that one histidine and two cysteine residues make the hydrophobic pocket that serves as the zinc-ligand in the active site of the enzyme (Rowlett et al., 1994; Bracey et al., 1994; Kimber \& Pai, 2000). In our active site analysis, we have predicted that Cys-153, Cys-216 and His-213 may constitute the zinc ligand of CAcp, whereas the zinc ligand of CAcyt may be made of Cys-87, Cys-139 and His-147. Crystallographic studies on $\beta$-CA from Cryptococcus neoformans show that an aspartate residue in the active site of $\beta$-CA activates water molecule for nucleophilic attack of $\mathrm{CO}_{2}$ by making a hydrogen bond with the $\mathrm{Zn}(\mathrm{II})$ - coordinated water molecule (Schlicker et al., 2009). This aspartate residue is also conserved in plant $\beta$-CAs and based on the analysis of conserved residues at the active site of chloroplastic and cytoplasmic $\beta$-CAs from $\mathrm{C}_{3}$ plants, we predicted Asp-155 of CAcp and Asp-89 of CAcyt as the respective residues of CAcp and CAcyt involved in proton transport; a feature necessary for the catalytic function of the enzyme. The 3D structures of CAcp and CAcyt, which were built using homology-based modeling, suggest that both the $\beta$-CAs of leucaena are octameric proteins with all the active site residues and zinc-binding residues conserved among CAcp and CAcyt.

$\beta$-CA is abundant in $\mathrm{C}_{3}$ plants and represent $\sim 2 \%$ of total protein in leaf tissues (Okabe et al., 1984). However, the information on individual abundance of chloroplastic and cytoplasmic $\beta$-CA in $\mathrm{C}_{3}$ plants is lacking. We designed and used specific primer sets for cacp and cacytin RT-PCR to identify tissue-specific transcript abundance of cacp and cacyt in leucaena. Our results demonstrate that transcript abundance of cacp was higher than that of cacyt in leaf and stem tissues while in root tissues the abundance of cacyt transcripts and cacp transcripts was similar. Transcript level of cacp was found maximum in leaf followed by stem and root tissu es whereas the maximum cacyt transcript level was observed in roots followed by leaf and stem tissues. Although the overall high $\beta$-CA content in $\mathrm{C}_{3}$ plants indicates their important physiological role, the varying abundance of chloroplastic and cytoplasmic $\beta$-CAs of leucaena in different tissues and also within the same tissue suggests that they have either different or complementary physiological role. Considering the alkaline nature of chloroplast 
stroma of $\mathrm{C}_{3}$ plants, their chloroplastic $\beta$-CAs have been proposed to be involved in the diffusion of $\mathrm{CO}_{2}$ into the chloroplast stroma, where $\mathrm{CO}_{2}$ and ribulosebis phosphate (RuBP) serve as the substrate for rubisco, which fixes the inorganic carbon into 3-phosphoglycerate (Badger \& Price, 1994). On the other hand, the cytoplasm of $\mathrm{C}_{3}$ plants has acidic environment in which the $\mathrm{HCO}_{3}{ }^{-}$levels are usually low. Additionally, the $\mathrm{CO}_{2}$ that diffuses through the cell wall may directly enter the chloroplast because the diffusion distance between the chloroplast envelope and the cell wall is typically small (Cowan, 1986; Badger $\&$ Price, 1994). This suggests that the cytoplasmic $\beta$-CAs may have little role, if any, in carbon fixation. However, considering that leucaena is well-adapted to alkaline soil condition, the abundance of cacyt in leucaena root tissues may be an adaptive measure of leucaena to improve buffering capacity of root cells in alkaline soils.

Photosynthesis potential of plants has been reported to be affected by some stress conditions such as drought and salt stress (Lawlor, 1995; Munns, 2002). Further study on correlation of photosynthesis with salt and drought stress demonstrated that these stress conditions predominantly limit the influx of $\mathrm{CO}_{2}$ in the leaves by decreasing the conductance of stomata and mesophyll (Flexas et al., 2004; Sudhir \& Murthy, 2004). Considering these studies and also the high abundance of $\beta$-CAs along with its biochemical role in carbon fixation, we hypothesized that the $\beta$-CAs in $\mathrm{C}_{3}$ plants might be involved in dealing with the physiological stress conditions that could limit the photosynthetic potential of $\mathrm{C}_{3}$ plants and therefore, the levels of $\beta$-CAs should be significantly increased under drought and salt stress conditions. To test this hypothesis, we studied the effects of drought and salt stress conditions on the transcript abundance of leucaena cacp and cacyt. As expected, we observed an enhanced expression of cacp and cacyt under both drought and salt stresses. In fact, the expression of cacytwas found to be higher in salt-stressed root tissues as compared to salt-stressed leaf and stem tissues. The overall expression of cacp was higher than cacyt in leaf and stem tissues under drought and salt stress conditions, however in root tissues cacyt expressed at higher levels compared to cacp. This may be because root is the first tissue to encounter these stresses and also may be because the root tissues lack chloroplasts and thereby it has a low level of cacp. Therefore, overexpression of cacyt in root tissues may be an adaptive measure of leucaena to withstand salinity stress. Drought and salt stress conditions lead to reduced $\mathrm{CO}_{2}$ solubility or decreased $\mathrm{CO}_{2}$ supply as a result of stomata closure. Previously, a similar increase in the expression of $\beta$-CA under drought and salt stress conditions was reported in a $\mathrm{C}_{4}$ plant, Pennise tumglaucum (Kaulet al., 2011).

Like drought and salt stress conditions, photosynthesis potential of plants is also affected by light and dark conditions. Also, the level of nucleus-encoded mRNAs for photosynthesis-related proteins have been shown to decrease under dark conditions (Giuliano et al., 1988; Chory et al., 1989). Therefore, we also tested the effects of light, dark, and bright light conditions on the expression levels of cacp and cacyt. The transcript levels of cacp and cacyt increased in light conditions in leaf and stem tissues only and the increase in the transcript levels of cacp was much higher than that of cacyt. Additionally, the increase in the expression of these transcripts got stabilized after $24 \mathrm{~h}$ of the treatment. The bright-light exposed plants, as compared to the control plants that were grown under moderate light 
conditions, exhibited only $\sim 2$ - to 4-fold increase in the transcript levels of cacp in the leaves, whereas transcript levels of cacyt exhibited only $\sim 2$-fold increase in the leaves. In the dark condition, the transcript levels of cacp and cacyt decreased in leaf and stem tissues and the overall decrease was observed more in the cacp levels than that of cacyt levels. The decrease in the levels of cacp transcripts and cacyt transcripts got stabilized after $24 \mathrm{~h}$ and $8 \mathrm{~h}$ time points, respectively and no further decrease in their expression levels was observed after these time points. A similar decrease in the level of $\beta$-CA was previously observed in $A$. thaliana in the dark condition (Fett \& Coleman, 1994). The increase or decrease in the expression of $\beta$-CAs under light or dark condition was found to change with time intervals. This indicates that $\beta$-CAs level may also be responsive to the normal circadian rhythm. The relatively higher expression of cacp as compared to cacyt under light condition may be because of its location and possibly crucial role in carbon fixation. Considering the alkaline microenvironment in chloroplast stroma, сасp is the major $\beta$-CA involved in inorganic carbon fixation into 3-phosphoglycerate (Badger \& Price, 1994). In contrast, the microenvironment of cytoplasm is acidic where the $\mathrm{HCO}_{3}{ }^{-}$levels is usually low, therefore, cacyt may have little or no role in carbon fixation under light condition (Cowan, 1986; Badger \& Price, 1994).

In summary, we have isolated cDNAs for chloroplastic and cytoplasmic $\beta$-CA from the $\mathrm{C}_{3}$ plant leucaena and we have shown that the transcript levels of cacp and cacyt increase under drought, salt and light conditions and decrease under dark condition. The differential expression of leucaena $\beta$-CAs under these conditions suggest that $\beta$-CAs may have a possible role in enhancing leucaena's ability to withstand abiotic stress conditions that affect the photosynthesis potential of the plant. However, it does not rule out another possibility in which $\beta$-CAs are only responsive to these stresses and do not play any active role in enhancing abiotic stress tolerance.

\section{Acknowledgements}

This research is supported mostly by a HATCH grant (HAW00551-H) and partially by the National Science Foundation Award No. CBET 08-27057.

\section{References}

Andersen, C. L., Jensen, J. L., \& Ørntoft, T. F. (2004). Normalization of real-time quantitative reverse transcription-PCR data: a model-based variance estimation approach to identify genes suited for normalization, applied to bladder and colon cancer data sets. Cancer Research, 64, 5245-5250. http://dx.doi.org/10.1158/0008-5472.CAN-04-0496

Arnold, K., Bordoli, L., Kopp, J., \& Schwede, T. (2006). The SWISS-MODEL workspace: a web-based environment for protein structure homology modelling. Bioinformatics, 22, 195-201. http://dx.doi.org/10.1093/bioinformatics/bti770

Badger, M. R., \& Price, G. D. (1994). The role of carbonic anhydrase in photosynthesis. Annual Review of Plant Physiology and Plant Molecular Biology, 45, 369-392. http://dx.doi.org/10.1146/annurev.pp.45.060194.002101

Bracey, M. H., Christiansen, J., Tovar, P., Cramer, S. P., \& Bartlett, S. G. (1994). Spinach 
carbonic anhydrase: investigation of the zinc-binding ligands by site-directed mutagenesis, elemental analysis, and EXAFS. Biochemistry, 33, 13126-13131. http://dx.doi.org/10.1021/bi00248a023

Burnell, J. N. (2000). Carbonic anhydrases of higher plants: an overview. InThe Carbonic Anhydrases: New Horizons, pp. 501-517 Eds W. R. Chegwidden, N. D. Carter \& Y. H. Edwards. Birkhäuser. http://dx.doi.org/10.1007/978-3-0348-8446-4_26

Burnell, J. N., Gibbs, M. J., \& Mason, J. G. (1990). Spinach chloroplastic carbonic anhydrase nucleotide sequence analysis of cDNA. Plant Physiology, 92, 37-40. http://dx.doi.org/10.1104/pp.92.1.37

Chory, J., Peto, C., Feinbaum, R., Pratt, L., \& Ausubel, F. (1989). Arabidopsis thaliana mutant that develops as a light-grown plant in the absence of light. Cell, 58, 991-999. http://dx.doi.org/10.1016/0092-8674(89)90950-1

Cowan, I. R. (1986). Economics of carbon fixation in higher plants. In: On the economy of plant form and function, 1986 Ed T. J. Givnish Cambridge. Cambridge University Press, pp. 133-170.

Emanuelsson, O., Nielsen, H., Brunak, S., \& von Heijne, G. (2000). Predicting subcellular localization of proteins based on their N-terminal amino acid sequence. Journal of Molecular Biology, 300, 1005-1016. http://dx.doi.org/10.1006/jmbi.2000.3903

Fabre, N., Reiter, I. M., Becuwe-Linka, N., Genty, B., \& Rumeau, D. (2007). Characterization and expression analysis of genes encoding $\alpha$ and $\beta$ carbonic anhydrases in Arabidopsis. Plant, Cell \& Environment, 30, 617-629. http://dx.doi.org/10.1111/j.1365-3040.2007.01651.x

Fawcett, T., Volokita, M., \& Bartlett, S. (1990). Spinach carbonic anhydrase primary structure deduced from the sequence of a cDNA clone. Journal of Biological Chemistry, 265, 5414-5417.

Fett, J. P., \& Coleman, J. R. (1994). Characterization and expression of two cDNAs encoding carbonic anhydrase in Arabidopsis thaliana. Plant Physiology, 105, 707-713. http://dx.doi.org/10.1104/pp.105.2.707

Flexas, J., Bota, J., Loreto, F., Cornic, G., \& Sharkey, T. D. (2004). Diffusive and metabolic limitations to photosynthesis under drought and salinity in $\mathrm{C}_{3}$ plants. Plant Biology, 6, 269-279. http://dx.doi.org/10.1055/s-2004-820867

Giuliano, G., Pichersky, E., Malik, V., Timko, M., Scolnik, P., \& Cashmore, A. (1988). An evolutionarily conserved protein binding sequence upstream of a plant light-regulated gene. Proceedings of the National Academy of Sciences, 85, 7089-7093. http://dx.doi.org/10.1073/pnas.85.19.7089

Götz, R., Gnann, A., \& Zimmermann, F. K. (1999). Deletion of the carbonic anhydrase-like gene NCE103 of the yeast Saccharomyces cerevisiae causes an oxygen-sensitive growth defect. Yeast, 15, 855-864. http://dx.doi.org/10.1002/(SICI)1097-0061(199907)15:10A<855::AID-YEA425>3.0.CO;2-C Guex, N., \& Peitsch, M. C. (1997). SWISS-MODEL and the Swiss-Pdb Viewer: An environment for comparative protein modeling. Electrophoresis, 18, 2714-2723. 
http://dx.doi.org/10.1002/elps.1150181505

Hatch, M. D., \& Burnell, J. N. (1990). Carbonic anhydrase activity in leaves and its role in the first step of $\mathrm{C}_{4}$ photosynthesis. Plant Physiology, 93, 825-828. http://dx.doi.org/10.1104/pp.93.2.825

Hewett-Emmett, D. (2000). Evolution and distribution of the carbonic anhydrase gene families. In:The Carbonic Anhydrases: New Horizons, pp. 29-78 Eds W. R. Chegwidden, N. D. Carter \& Y. H. Edwards. Birkhäuser. http://dx.doi.org/10.1007/978-3-0348-8446-4_3

Hewett-Emmett, D., \& Tashian, R. E. (1996). Functional Diversity, Conservation, and Convergence in the Evolution of the $\alpha-, \beta$-, and $\gamma$-Carbonic Anhydrase Gene Families. Molecular Phylogenetics and Evolution, 5, 50-77. http://dx.doi.org/10.1006/mpev.1996.0006

Kamal, A. H. M., Cho, K., Kim, D.-E., Uozumi, N., Chung, K.-Y., Lee, S. Y., ...Woo, S. H. (2012). Changes in physiology and protein abundance in salt-stressed wheat chloroplasts. Molecular Biology Reports, 39, 9059-9074. http://dx.doi.org/10.1007/s11033-012-1777-7

Kaul, T., Reddy, P. S., Mahanty, S., Thirulogachandar, V., Reddy, R. A., Kumar, B., ...Reddy, M. K. (2011). Biochemical and molecular characterization of stress-induced $\beta$-carbonic anhydrase from a $\mathrm{C}_{4}$ plant, Pennisetum glaucum. Journal of Plant Physiology, 168, 601-610. http://dx.doi.org/10.1016/j.jplph.2010.08.007

Kimber, M. S., \& Pai, E. F. (2000). The active site architecture of Pisum sativum $\beta$-carbonic anhydrase is a mirror image of that of $\alpha$-carbonic anhydrases. The EMBO Journal, 19, 1407-1418. http://dx.doi.org/10.1093/emboj/19.7.1407

Lawlor, D. W. (1995). The effects of water deficit on photosynthesis. In:Environment and plant metabolism: flexibility and acclimation, pp. 129-160 Ed N. Smirnoff. BIOS Scientific Publishers.

Livak, K. J., \& Schmittgen, T. D. (2001). Analysis of relative gene expression data using real-time quantitative PCR and the $2^{-\Delta \Delta \mathrm{CT}}$ Method. Methods, 25, 402-408. http://dx.doi.org/10.1006/meth.2001.1262

Ludwig, M. (2012). Carbonic anhydrase and the molecular evolution of $\mathrm{C}_{4}$ photosynthesis. Plant, Cell \& Environment,35, 22-37. http://dx.doi.org/10.1111/j.1365-3040.2011.02364.x

McGuffin, L. J., Bryson, K., \& Jones, D. T. (2000). The PSIPRED protein structure prediction server. Bioinformatics, $16, \quad 404-405$. http://dx.doi.org/10.1093/bioinformatics/16.4.404

Moroney, J. V., Ma, Y., Frey, W. D., Fusilier, K. A., Pham, T. T., Simms, T. A., DiMario, R. J., .. Mukherjee, B. (2011). The carbonic anhydrase isoforms of Chlamydomonas reinhardtii: intracellular location, expression, and physiological roles. Photosynthesis Research, 109, 133-149. http://dx.doi.org/10.1007/s11120-011-9635-3

Munns, R. (2002). Comparative physiology of salt and water stress. Plant, Cell \& Environment, 25, 239-250. http://dx.doi.org/10.1046/j.0016-8025.2001.00808.x

Negi, V. S., Pal, A., Singh, R., \& Borthakur, D. (2011). Identification of species-specific genes from Leucaena leucocephala using interspecies suppression subtractive hybridisation. Annals of Applied Biology, 159, 387-398. http://dx.doi.org/10.1111/j.1744-7348.2011.00506.x Okabe, K., Yang, S. Y., Tsuzuki, M., \& Miyachi, S. (1984). Carbonic anhydrase: its content in 
spinach leaves and its taxonomic diversity studied with anti-spinach leaf carbonic anhydrase antibody. Plant Science Letters, 33, 145-153. http://dx.doi.org/10.1016/0304-4211(84)90004-X

Pal, A., Negi, V. S., \& Borthakur, D. (2012). Efficient in vitro regeneration of Leucaena leucocephala using immature zygotic embryos as explants. Agroforestry Systems, 84, 131-140. http://dx.doi.org/10.1007/s10457-011-9438-8

Rowlett, R. S. (2010). Structure and catalytic mechanism of the $\beta$-carbonic anhydrases. Biochimica et Biophysica Acta (BBA)-Proteins and Proteomics, 1804, 362-373. http://dx.doi.org/10.1016/j.bbapap.2009.08.002

Rowlett, R. S., Chance, M. R., Wirt, M. D., Sidelinger, D. E., Royal, J. R., Woodroffe, M., ... Lam, M. G. (1994). Kinetic and structural characterization of spinach carbonic anhydrase. Biochemistry, 33, 13967-13976.http://dx.doi.org/10.1021/bi00251a003

Schlicker, C., Hall, R. A., Vullo, D., Middelhaufe, S., Gertz, M., Supuran, C. T., ... Steegborn, C. (2009). Structure and inhibition of the $\mathrm{CO}_{2}$-sensing carbonic anhydrase Can2 from the pathogenic fungus Cryptococcus neoformans. Journal of Molecular Biology, 385, 1207-1220. http://dx.doi.org/10.1016/j.jmb.2008.11.037

Schneider, C. A., Rasband, W. S., Eliceiri, K. W., Schindelin, J., Arganda-Carreras, I., Frise, ... Preibisch, S. (2012). 671 nih image to imageJ: 25 years of image analysis. Nature methods ,9. http://dx.doi.org/10.1038/nmeth.2089

Schwede, T., Kopp, J., Guex, N., \& Peitsch, M. C. (2003). SWISS-MODEL: an automated protein homology-modeling server. Nucleic Acids Research, 31, 3381-3385. http://dx.doi.org/10.1093/nar/gkg520

Sly, W. S., \& Hu, P. Y. (1995). Human carbonic anhydrases and carbonic anhydrase deficiencies. Annual Review of Biochemistry, 64, 375-401. http://dx.doi.org/10.1146/annurev.bi.64.070195.002111

Smith, K. S., Cosper, N. J., Stalhandske, C., Scott, R. A., \& Ferry, J. G. (2000). Structural and kinetic characterization of an archaeal $\beta$-class carbonic anhydrase. Journal of Bacteriology, 182, 6605-6613. http://dx.doi.org/10.1128/JB.182.23.6605-6613.2000

Smith, K. S., Ingram-Smith, C., \& Ferry, J. G. (2002). Roles of the conserved aspartate and arginine in the catalytic mechanism of an archaeal $\beta$-class carbonic anhydrase. Journal of Bacteriology, 184, 4240-4245. http://dx.doi.org/10.1128/JB.184.15.4240-4245.2002

Strop, P., Smith, K. S., Iverson, T. M., Ferry, J. G., \& Rees, D. C. (2001). Crystal structure of the "cab"-type $\beta$ class carbonic anhydrase from the archaeon Methanobacterium thermoautotrophicum. Journal of Biological Chemistry, 276, 10299-10305. http://dx.doi.org/10.1074/jbc.M009182200

Sudhir, P., \& Murthy, S. D. S. (2004). Effects of salt stress on basic processes of photosynthesis. Photosynthetica, 42, 481-486.http://dx.doi.org/10.1007/S11099-005-0001-6

Syrjänen, L., Tolvanen, M., Hilvo, M., Olatubosun, A., Innocenti, A., Scozzafava, A., ... Supuran, C. T. (2010). Characterization of the first beta-class carbonic anhydrase from an arthropod (Drosophila melanogaster) and phylogenetic analysis of beta-class carbonic anhydrases in invertebrates. BMC Biochemistry, $11, \quad 28$. 
http://dx.doi.org/10.1186/1471-2091-11-28

Tachibana, M., Allen, A. E., Kikutani, S., Endo, Y., Bowler, C., \& Matsuda, Y. (2011). Localization of putative carbonic anhydrases in two marine diatoms, Phaeodactylum tricornutum and Thalassiosira pseudonana. Photosynthesis Research, 109, 205-221. http://dx.doi.org/10.1007/s11120-011-9634-4

Tetu, S. G., Tanz, S. K., Vella, N., Burnell, J. N., \& Ludwig, M. (2007). The Flaveria bidentis $\beta$-carbonic anhydrase gene family encodes cytosolic and chloroplastic isoforms demonstrating distinct organ-specific expression patterns. Plant Physiology, 144, 1316-1327. http://dx.doi.org/10.1104/pp.107.098152

Zimmerman, S. A., \& Ferry, J. G. (2008). The $\beta$ and $\gamma$ Classes of Carbonic Anhydrase. Current Pharmaceutical Design, 14, 716-721. http://dx.doi.org/10.2174/138161208783877929

\section{Copyright Disclaimer}

Copyright reserved by the author(s).

This article is an open-access article distributed under the terms and conditions of the Creative Commons Attribution license (http://creativecommons.org/licenses/by/3.0/). 